\title{
El libro de Tobías como manual de acompañamiento espiritual
}

\section{Tobiah's book as a handbook of spiritual direction}

\author{
Álvaro Pereira Delgado \\ Facultad de Teología San Isidoro de Sevilla \\ apereiradelgado@gmail.com \\ ID ORCID 000-0002-7124-0162
}

Resumen: El libro de Tobías ha sido recibido por la tradición de la iglesia como un verdadero manual de dirección espiritual. El presente artículo trata de identificar algunas de las enseñanzas que el camino que emprende Tobías acompañado por el ángel Rafael puede aportar a una visión renovada del acompañamiento espiritual. El autor utiliza una metodología interdisciplinar basada en tres instrumentos: el análisis exegético del relato, las aportaciones de algunos maestros en psicología y espiritualidad, y la experiencia propia del trabajo con jóvenes.

Palabras claves: Tobías, acompañamiento espiritual, pastoral juvenil, maduración

\begin{abstract}
Tobiah's book has been received by the church tradition as a true handbook of spiritual direction. This article tries to renew the idea of spiritual accompaniment by studying the path that Tobiah undertakes accompanied by the angel Raphael. The author uses an interdisciplinary methodology based in three instruments: the exegetical analysis of the story, the contributions of psychology and spirituality, and the own experience of working with young people.
\end{abstract}

Keywords: Tobiah, spiritual accompaniment, youth pastoral, maturation

Entre las perlas bíblicas del Antiguo Testamento se encuentra el libro de Tobías. Se trata de un auténtico manual para acompañantes. El libro, novela ejemplar judía escrita en la diáspora en torno al 200 a. C. ${ }^{1}$, comienza con el relato en primera persona de la vida de un judío

1 Cf. JoséVílchez, Tobías y Judit (Estella, Verbo Divino, 2000), 34-35. Esta es la mejor monografía en castellano sobre el libro de Tobías hasta la fecha. Recientemente, el sacerdote y profesor de la diócesis de Málaga, Emilio López NAVAs, ha publicado una excelente monografía sobre la acción de gracias del final del libro: De la 
desterrado en Nínive, el bueno de Tobit ${ }^{2}$, que intenta ser fiel a Dios realizando buenas obras (enterrando a sus compatriotas muertos, aunque estuviera prohibido; invitando a comer a los pobres, etc.). A pesar de su fidelidad a la Ley mosaica, cosa que le acarrea las críticas de su propia mujer, se queda ciego porque, durmiendo bajo un árbol, le cae el excremento caliente de unos gorriones. Entonces Tobit reza a Dios. El lector, que espera la respuesta divina a una oración tan piadosa, escucha sin embargo una nueva historia de otra persona justa a quien también le van mal las cosas: Sara, hija de Ragüiel ${ }^{3}$ y pariente de Tobit. Sara, a pesar de su fidelidad a la Ley (pureza de costumbres, honra de sus padres, etc.), ha visto morir a sus siete maridos durante la noche de bodas por obra del demonio Asmodeo. También ella ora a Dios con piedad.

Las dos súplicas paralelas de Tobit $(3,2-6)$ y Sara $(3,11-15)$ ponen en marcha la acción del relato. Dice el texto: «En aquel instante, la oración de ambos fue escuchada delante de la gloria de Dios, el cual envió al ángel Rafael para curarlos» (3,16-16). Dios responde enviando al ángel Rafael, nuestro modelo de acompañante ${ }^{4}$.

\section{EL ACOMPAÑANTE COMO ÁNGEL}

Con el envío divino del ángel Rafael, recibimos la primera enseñanza sobre el acompañamiento y, quizás, la más importante ${ }^{5}$ : el

oscuridad a Jerusalén. Estudio exegético-teológico de Tob 13 (Tesis 66; Estella, Verbo Divino, 2016).

2 En el libro aparecen tres generaciones de hombres con nombres parecidos: Tobiel, el abuelo, cuyo nombre significa «Dios es mi bien» (Tob 1,1); Tobit, el padre, apócope de «Yahvé es mi bien» (1,1); y Tobías, el hijo, que también significa «Yahvé es mi bien» $(1,9)$.

3 De nuevo Ragüel es un nombre de significado evocador: «Dios es amigo».

4 Ya san Francisco de Sales decía que el director espiritual debía ser como un ángel, poniendo explícitamente el ejemplo de Rafael y Tobías: «Habiéndole mandado a Tobías el menor que fuese a Ragués, dijo: "De ninguna manera sé el camino". "Anda (replicó el padre), y busca algún hombre que te encamine" (Tob 5,2.4). De la misma manera te digo yo, Filotea mía. ¿Quieres con más seguridad caminar a la devoción? Busca, pues, algún hombre virtuoso que te adiestre y guíe»: San Francisco de SALeS, La verdadera devoción § I.4 (Sevilla, Apostolado Mariano, 2000) p. 16.

5 Usaré indistintamente los términos «acompañante», «director» o «guía» espiritual, aunque el lector debe ser consciente de las diferencias. Luis Jorge GonZÁLEZ, «Acompañamiento espiritual», Teresianum 52 (2001) 790 (789-807), hace un buen 
acompañante no debe anclar su labor en las aguas movedizas de su experiencia de vida, de su capacitación bíblica, psicológica o espiritual. Ser acompañante, en lenguaje creyente, significa ante todo saberse enviado a desarrollar una misión que es respuesta a una oración de fe, como la de Tobit y Sara. El acompañante debe ser un «ángel», es decir, un mensajero de Dios. Esta constatación impregna de humildad y trascendencia su labor, pues se trata de una tarea de mediación: Dios es siempre el maestro interior cuyo instrumento es el acompañante ${ }^{6}$. Si tomamos conciencia de ello, los directores o acompañantes espirituales rezaríamos más y nos aprestaríamos a comenzar cada sesión con la misma gravedad que Moisés al descalzarse ante la zarza ardiente. El mismo libro de Tobías hace explícita esta prioridad de la oración en la labor del acompañamiento. Cuando el ángel revela su identidad, Rafael confiesa a Tobit que había estado delante de Dios cuando tanto él como Sara elevaban sus súplicas: «cuando tú y Sara orabais, era yo quien presentaba el memorial de vuestras oraciones ante la gloria del Señor, y lo mismo cuando enterrabas a los muertos» (Tob 12,12.15).

Por otro lado, el envío del ángel Rafael responde a una historia previa: en la corta distancia, las desgracias de Tobit y Sara; en la larga distancia, el drama del destierro de los judíos. La fe bíblica es esencialmente histórica. Como acompañante, he cometido frecuentemente el error de intentar comenzar desde cero, olvidándome que toda persona que solicita ser acompañada lleva sobre sus espaldas la mochila de una historia propia, de corta y larga distancia, que es necesario acoger, comprender y presentar ante Dios en la oración. Escuchar y hacerse cargo de esta historia debe preceder a toda

comentario al respecto: «Se pretende, por tanto, que el acompañante espiritual cumpla los mismos cometidos de la dirección espiritual, eliminando los posibles excesos de ésta, como el autoritarismo desmesurado, e incluyendo las aportaciones mejores de la experiencia postconciliar y de la psicología contemporánea».

6 La teología espiritual ha identificado al Espíritu Santo como la persona de la Trinidad que realiza dicha labor de mediación en el alma humana. Así afirmaba san Juan de la Cruz: «Adviertan los que guían las almas y consideren que el principal agente y guía y movedor de las almas en este negocio no son ellos, sino el Espíritu Santo, que nunca pierde cuidado de ellas, y que ellos solo son instrumentos para enderezarlas en la perfección por la fe y ley de Dios, según el espíritu que Dios va dando a cada una»: Llama de amor viva 3.46 (BAC 15, p. 999). Cf. José CASERo RodríGUEZ, «El Espíritu Santo, agente principal en la dirección del alma», Teología Espiritual 23 (1979) 131-180. 
palabra de orientación. Así pues, el acompañante debe empezar su labor desde la oración creyente y la escucha profunda de la historia personal y social del acompañado. Pero, antes de adentrarnos en esta labor fascinante, aprendamos cómo el libro de Tobías nos enseña a encontrar un buen acompañante.

\section{ENCONTRAR UN GUÍA AL INICIO DEL VIAJE}

El relato del libro de Tobías sigue con el amplio testamento espiritual que lega Tobit a su hijo en el cap. 4, recomendándole una serie muy completa de obras buenas. Termina diciéndole que tiene la mitad de su hacienda en un país lejano y le exhorta a ir a recogerla. El joven Tobías responde al mandato de su padre y se apresta a comenzar su largo viaje. Antes, su padre le aconseja buscar a alguien de confianza que le acompañe (Tob 5,3). Tobías es fiel a esta recomendación y da con un misterioso israelita llamado Azarías — quien el lector ya reconoce como el ángel Rafael— que se ofrece para acompañarlo. En los tratos entre Tobit, Tobías y Azarías-Rafael hay pequeños detalles muy luminosos que ofrecen finas enseñanzas a la hora de desarrollar un saludable y creyente acompañamiento espiritual.

En primer lugar, fijémonos en el proyecto del acompañado: el viaje de Tobías. Todo hijo recibe una herencia o misión espiritual de sus padres: emprender el viaje de la vida. En la Antigüedad los viajes eran peligrosos. Hoy nuestros viajes son más placenteros y seguros, y tenemos menos miedo a viajar. Por ello, la metáfora del viaje vital puede quedar desfigurada. Sin embargo, «la sabiduría bíblica desenmascara con acierto cualquier pretensión de creerse en posesión absoluta del propio camino o de hacerlo en solitario..." hay un camino que uno cree recto que va a parar a la muerte" (Prov 14,12)» ${ }^{7}$. Nuestra condición de homo viator (ser en camino) nos exige buscar apoyo, pedir ayuda, aceptar que la vida se recorre mejor «de dos en dos» (Mc 6,7).

El viaje de la vida requiere, por un lado, renuncias y liberaciones: separarse del seno materno y de la protección paterna, arriesgar en rutas desconocidas. Muchos jóvenes hoy, en cambio, no quieren arriesgar, o lo que es peor, no pueden porque su generación

7 Dolores AleiXandre, «Imágenes bíblicas para el acompañamiento», Sal Terrae 1004 (1997) 645 (641-657). 
precedente los ha inhabilitado para el esfuerzo y para la libertad ${ }^{8}$. Tienden a estar demasiado acomodados en casa, lo que no ayuda a afrontar los retos, a veces dolorosos, y siempre esforzados, de la vida. Muchos padres, además, pactan en silencio con sus hijos, y no les importa adoptar durante toda la vida la labor de madres-cocodrilo o padres-helicóptero, siempre dispuestos a proteger, rescatar, evitar un sufrimiento a sus hijos ${ }^{9}$. De hecho, la madre de Tobías echa en cara a su marido que haya impulsado a su hijo a emprender tan arriesgado viaje — ¡la vida siempre es un viaje arriesgado! — y le dice a Tobit: "¿Por qué has dejado marchar a mi hijo? Él es el báculo de nuestra vejez. Siempre ha estado con nosotros» (Tob 5,18). No obstante, sin riesgo no hay enriquecimiento y maduración. Todo joven debe, como Tobías, emprender el viaje de la vida. Pero esta osada empresa también requiere cierto acompañamiento. El primer acompañamiento será materno y paterno: aunque Tobías esté lejos, sabrá siempre adónde va - a buscar la herencia de la familia para perpetuar el don de la vida — y quién le espera — su familia sigue en casa—. Tobías no olvida jamás que viaja acompañado por el amor de sus padres. Pero, además, el padre recomienda a su hijo un buen guía para el camino, así encuentra a Rafael, alias Azarías. Muchos jóvenes hoy, en cambio, quieren realizar el viaje de sus años fundacionales vanidosamente liberados de toda tutela, olvidando de forma temeraria la memoria de su casa y la herencia espiritual de su familia. Corren el peligro, entonces, de reproducir muchos de los dramas familiares de los que querían huir ${ }^{10}$.Viajar en riesgo y libertad, pero siempre reconociendo la compañía de los testigos con experiencia: esa es una buena realización del viaje de la vida.

En segundo lugar, este viaje, en el caso de Tobías, tiene un sentido: debe ir a Ragués de Media (Tob 1,14; 4,1.20), donde están los bienes de su padre. Esta noticia también alberga una enseñanza para

8 Recuérdese el viejo, pero no menos actual libro de Erich Fromm, Miedo a la libertad (Buenos Aires, Editorial Paidós, 2005; primera edición de 1941).

9 Cf. las explicaciones sobre estas cuestiones del psicoanalista Massimo ReCALCATI sobre el padre: El complejo de Telémaco. Padres e hijos tras el ocaso del progenitor (Barcelona, Anagrama, 2014); y sobre la madre: Las manos de la madre. Deseo, fantasmas y herencia de lo materno (Barcelona, Anagrama, 2018).

10 Cf. en este sentido el estudio de Massimo ReCalCATI, El secreto del hijo (Barcelona, Anagrama, 2020), sobre Edipo, como mala realización de la filiación, y sobre el Hijo pródigo, como ejemplo saludable de madurez y libertad. 
nosotros hoy: el viaje de cada joven no es un movimiento sin rumbo, sino que debe ser vivido como un itinerario vocacional mediante el cual, a pesar de las fatigas, fracasos y tensiones, se busca por todos los medios caminar hacia una meta, aunque no esté clara cuál es. En cristiano, esa meta se llama confiar en la providencia divina, realizar el proyecto del Creador y llegar así a la santidad, vestíbulo de la entrada al cielo. Pero esta meta implica lógicamente ponerse en camino. Nadie llega si no parte. «No hay providencia alguna para el hombre que permanece sentado. La providencia conoce únicamente al hombre que camina» ${ }^{11}$.

En tercer lugar, es iluminador reparar en la pregunta de Tobías cuando encuentra a su posible guía: " ¿Conoces el camino que lleva a Media?" Respondió el ángel: "Sí. He estado allí muchas veces y conozco bien todos los caminos"» (Tob 5,5-6a.10). Esta es una de las condiciones fundamentales de un buen acompañante o guía espiritual: haber hecho él mismo el camino; haber ido y venido muchas veces; es decir, haber sido él mismo acompañado, conocer en carne propia la fatigosa pero apasionante experiencia del viaje de la vida, de las vías de Dios y de los propios demonios, de la compañía madura de alguien con experiencia. ¿Cómo podrá acompañar a otro el que no ha aprendido primero cuáles son los caminos que recorrer?

En cuarto lugar, Tobit describe a su hijo algunas de las características propias del buen acompañante: «Busca un hombre de confianza que vaya contigo, y lo tomaremos a sueldo hasta tu vuelta» (Tob 5,3). La pregunta por el crédito del que acompaña es siempre una cuestión decisiva. También el anciano Ben Sira, escarmentado por sus muchos años, precave al aprendiz de sabio contra aquellos consejeros que buscan más el propio interés que el de sus aconsejados:

Todo consejero da consejos, pero hay quien aconseja en su interés. Ten cuidado con el consejero, entérate primero de qué necesita, porque en su propio provecho te aconsejará; no sea que eche sobre ti la suerte y te diga: «Vas por buen camino», y luego se quede esperando para ver qué te sucede [...] No te aconsejes con una mujer sobre su rival, con un cobarde sobre la guerra, con un negociante sobre el comercio, con un comprador sobre la venta, con un envidioso sobre la gratitud, con un tacaño sobre la generosidad, con un perezoso sobre trabajo alguno, con un empleado eventual sobre el fin de una obra, con un siervo holgazán sobre una gran tarea: no cuentes con

11 Paul BeAuchamp, Los salmos, noche y día (Madrid, Cristiandad, 1981)147. 
ninguno de ellos para un consejo. Recurre siempre a un hombre piadoso, de quien sabes seguro que guarda los mandamientos, que comparte tus anhelos y que, si caes, sufrirá contigo [...] Pero, sobre todo, suplica al Altísimo, para que dirija tus pasos en la verdad.

(Eclesiástico 37,7-15)

Así pues, el acompañante debería ser alguien digno de fe, que no traicione al joven ni lo engañe. Más adelante esta característica se concretará para Tobit en saber si es israelita de una familia conocida por él. También el acompañante, ciertamente, debería ser una persona con experiencia de fe y vida, alguien que se sepa bendecido por recibir el glorioso nombre de cristiano. Sin embargo, el verdadero hontanar de la autoridad del acompañante se irá fundando en su compromiso servicial y abnegado en bien del acompañado. Solo el camino demostrará la verdad $^{12}$. De hecho, veremos a lo largo del texto la valía del guía Rafael. Basten como tarjeta de presentación las palabras que salen de su boca en el cap. 5: «Te espero» $(5,8)$; «Que la alegría sea contigo» $(5,10)$; «Ten confianza» $(5,10)$. ¡Son excelentes palabras para una sesión de acompañamiento cualquiera!

Además, Tobit dice que el acompañante debe ir «contigo» $(5,3)$. Todo proceso de acompañamiento - hay que reconocerlo- no solo implica el viaje del acompañado, también conlleva el viaje de quien acompaña. No solo arriesga el acompañado, también se expone el guía. ¿Está el acompañante dispuesto a comprometerse? Hay que rezar bien antes de comenzar.

La última palabra de Tobit a Tobías consiste en el contrato: «Lo tomaremos a sueldo» $(5,3)$. Lógicamente no estoy sugiriendo que el acompañamiento se debiera pagar, aunque tampoco debería ser minusvalorado por su estatuto de gratuidad. Con todo, este «contrato» entre Tobías y Rafael sugiere que es aconsejable establecer una relación objetiva y formal entre el acompañante y el acompañado. Muchos jóvenes tienden a creer que sus acompañantes son

12 «El crédito del guía, necesario para hacerse confiable, no se apoya en la imponencia social, ni en sus títulos, ni en su lenguaje arcano, ni en su pose hierática, ni en su juego de influencias - recursos bastante habituales entre los"expertos" - . Se apoya desnudamente en el compromiso de su servicio ejercido con humildad y cercanía, en su radical desinterés, en su accesibilidad, en su palabra anclada al anuncio del evangelio»: Germán ARANA, «El acompañamiento espiritual durante el desarrollo del ministerio», El acompañamiento espiritual en la vida y ministerio del sacerdote (Sevilla, Arzobispado de Sevilla, 2001) 65. 
sus amigos. No es así. Se trata más bien de una relación formal de confianza por la que los dos inician un viaje con una misión concreta: ayudar al acompañado a buscar y discernir la voluntad de Dios en su vida y desarrollarla con alegría. Las demás cosas son secundarias y no pueden oscurecer esta misión fundamental. Además, esta relación de ayuda y colaboración, como un contrato laboral, también puede cesar en un momento dado: porque el acompañado no se siente comprendido después de un tiempo caminando juntos; porque el acompañante no cree que esté haciendo bien su labor o no cree que el acompañado esté respondiendo; o, simplemente, porque llega la hora de caminar junto a otra persona.

\section{EL VIAJE Y LA COMPAÑÍA}

«Partió el muchacho en compañía del ángel, y el perro los seguía» (Tob 6,1). Con la misma alegría que el perrillo, Tobías y Rafael emprenden un viaje lleno de vicisitudes y dificultades. Nuestro ángelacompañante hace el viaje con Tobit, lo anima y lo guía. Está siempre disponible. Sabe callar y sabe hablar cuando es preciso, dejando que Tobías sea el protagonista del viaje, pero dándole indicaciones cuando es necesario. Por ejemplo, cuando encuentra un pez, Rafael le dice con determinación: «iAgarra el pez y tenlo bien sujeto!» $(6,4)$. El ángel le dice que lo prepare y lo guarde, porque le podría ser útil. Andando el relato, sabremos que con este pez Tobías curará la ceguera de su padre y el mal de su futura esposa. En esta anécdota aprendemos algo también crucial para la labor del acompañante. El guía espiritual debe ir identificando y dando herramientas al joven que más adelante, no se sabe cuándo, le serán útiles en su vida. Algunas de estas herramientas serán el aprendizaje de la oración y la gramática del Espíritu, el hábito de examinar la conciencia y reconocer sus autoengaños, la necesidad de una comunidad con la que compartir, la capacidad de ser fuertes $y$, al mismo tiempo, aceptar que su debilidad es amada por Dios, etc.

En el viaje no solo el acompañante tiene que estar diligente y activo. También el acompañado debe establecer una relación de confianza con el acompañante. Tobías escucha las propuestas de Rafael, dialoga con él y obedece a sus recomendaciones (léase el cap. 6), revelándose así como alguien sabio, ya que «el sabio se deja aconsejar» (Proverbios 13,10b). De igual modo, el joven debería reconocer que 
el acompañante no es su amigo, alguien de igual a igual, sino una persona con autoridad y experiencia de vida que le será de mucho provecho para avanzar en su camino.

Tobías y Rafael llegan a la casa de Ragüel en Ecbátana (Media). Rafael le dice a Tobías que Sara es la mujer que está buscando, es de su parentela. Tobías se enamora de ella y la pide en matrimonio a su padre. En la escena se repite, sin embargo, el problema de Sara. Tobías duda, iy si muero como los maridos anteriores y dejo sin descendencia a mis padres? En este momento, el ángel-acompañante anima a Tobías a que sea valiente, apueste por realizar su vocación, a pesar de las dudas y los peligros. Y le da una serie de consejos que realizará con el pez para liberar a Sara del demonio y así consumar su proyecto matrimonial. Aquí aprendemos que el verdadero acompañante, como Rafael («Dios cura») ${ }^{13}$, es aquel que sana y libera, tanto exterior como interiormente, al joven. No es alguien que refuerza sus heridas interiores, sino que le ayuda a liberarse de ellas en contacto con Dios.

Es primordial, por otro lado, reconocer que Rafael es exquisito en sus actuaciones: interviene cuando su consejo es necesario, pero sabe apartarse cuando su presencia es indiscreta o simplemente superflua. El buen acompañante del joven viajero se sabe actor secundario de la historia de otro; por ello, siempre trata de permanecer en un segundo plano. Es Tobías el que tiene que hablar con Ragüel, rezar junto a Sara y realizar con el pez el conjuro que expulse el demonio. De hecho, al final de su viaje es Tobías el que toma la iniciativa y manda a

13 En una ordenación de presbíteros, BenEDicto XVI explicaba así la labor sanadora de Rafael: «El libro de Tobías refiere dos tareas emblemáticas de curación que realiza el arcángel Rafael. Cura la comunión perturbada entre el hombre y la mujer. Cura su amor. Expulsa los demonios que, siempre de nuevo, desgarran y destruyen su amor. Purifica el clima entre los dos y les da la capacidad de acogerse mutuamente para siempre. [...] En segundo lugar, el libro de Tobías habla de la curación de la ceguera. Todos sabemos que hoy nos amenaza seriamente la ceguera con respecto a Dios. Hoy es muy grande el peligro de que, ante todo lo que sabemos sobre las cosas materiales y lo que con ellas podemos hacer, nos hagamos ciegos con respecto a la luz de Dios. Curar esta ceguera mediante el mensaje de la fe y el testimonio del amor es el servicio de Rafael [...] La verdadera herida del alma, el motivo de todas nuestras demás heridas, es el pecado.Y solo podemos ser curados, solo podemos ser redimidos, si existe un perdón en virtud del poder de Dios, en virtud del poder del amor de Cristo» (Basílica de San Pedro. Sábado 29 de septiembre de 2007). 
Azarías-Rafael por el dinero de su padre a Ragués $(9,1-6)$ porque no quiere demorarse en su vuelta. El joven que, al inicio del viaje, buscaba a alguien que conociera los caminos, ya es un adulto responsable que sabe tomar decisiones autónomamente ${ }^{14}$. De aquí aprendemos que el buen guía espiritual siempre está en segundo plano, no sustituye al joven, respeta con delicadeza su libertad. El objetivo último tanto del padre como del acompañante es hacerse progresivamente inútil, para dejar al hijo madurar y convertirse en adulto en la vida y en la fe, de manera que él también el día de mañana acompañe a otros. Ya lo decía Juan el Bautista, otro modelo de guía espiritual: «Es necesario que él crezca y que yo mengüe» (Jn 3,30$)^{15}$.

Antes de continuar reparamos brevemente en la figura del demonio Asmodeo. Si el ángel bueno, Rafael, ayuda a Tobías, el demonio Asmodeo aflige a Sara ${ }^{16}$. La disputa entre estos dos seres espirituales revela una verdad profunda: la lucha que se libra en el corazón de cada joven es un caso particular del combate cósmico que Dios libra contra las fuerzas del mal, según narra el Apocalipsis. No hay equidistancia, sin embargo, en esta guerra: Dios ya ha vencido por la muerte y resurrección de su Hijo. Las batallas personales y eclesiales actuales son solo coletazos finales que preludian la gran

14 En el texto del Eclesiástico que hemos citado antes, Ben Sira termina diciendo: «Atiende al consejo de tu corazón, porque nadie te será más fiel. Pues la propia conciencia suele avisar mejor que siete centinelas apostados en su torre de vigilancia. Pero, sobre todo, suplica al Altísimo, para que dirija tus pasos en la verdad» (Eclo 37,13-15). Así pues, Ben Sira recomienda buscar un consejero fiel, pero también escuchar la voz de la conciencia y, en última instancia, suplicar a Dios. Se equivocaría el que pensara que el mejor acompañante hace superfluo el discernimiento propio y el diálogo con Dios.

15 Contra el peligro de los presbíteros que realizan una dirección espiritual autocentrada, afirma Germán Arana: «las insidias de la posesividad, del excesivo protagonismo, el sentido desviante de una autoridad centrada en el presbítero, o de una relación que tienda a gratificar sus carencias afectivas, o su imagen social, no solo muñirán una relación psicológicamente problemática, sino que harán fracasar en ella el verdadero sentido del ministerio»o, por extensión, de cualquier relación de acompañamiento. Cf. ARANA, «El acompañamiento espiritual», 66.

16 En el Testamento de Salomón (siglo II d. C.), Asmodeo dice de sí mismo: «Mi función es la de conspirar contra los nuevos esposos, para impedirles que se conozcan. Destruyo la belleza de las vírgenes y cambio sus corazones. Llevo a los hombres a accesos de locura y de codicia, y aunque tengan sus mujeres, las dejan por mujeres que son de otros maridos, aunque pequen y caigan en actos homicidas». Cita tomada de Daniel Doré, El libro de Tobit o el secreto del rey (Cuadernos Bíblicos 101; Estella, Verbo Divino, 2000) 20. 
victoria del cordero. Esta verdad, de índole creyente, debe llevar al joven a reconocer que él es misteriosamente tentado, aunque nunca por encima de sus fuerzas (cf. 1 Cor 10,13), y que debe suplicar el auxilio divino para salir airoso. Asimismo, el acompañante debe ser realista y ayudar al joven a descubrir los engaños y tentaciones del mal espíritu que oprimen y traicionan al joven. El hombre moderno se ha olvidado de que el pecado ofusca su entendimiento. La relación de acompañamiento, en cambio, será también una paciente y trabajosa tarea de iluminación, reconocimiento y liberación. Así lo expresa con palabras clarividentes el padre Arana:

Nuestra peregrinación presente, mientras dura, está sujeta a trampas, tentaciones y oscurecimientos con respecto a su objetivo final. Estas dificultades que Ignacio de Loyola las reúne en la figura arquetípica del «enemigo» tienen diverso asiento: nosotros mismos, como producto de la inercia de desviaciones pasadas; los universos simbólicos y axiológicos de nuestra cultura, atravesados por tendencias idolátricas ampliamente compartidas; y los espíritus enemigos de Dios y su Cristo. Pero todas esas formas tienen una funcionalidad común: quebrar el crecimiento del hombre en Cristo según el evangelio. En ese marco de lucha escatológica en el que discurre toda existencia humana, el servicio de ayuda pastoral personalizada no es neutro. Tiene un carácter militante, comprometido. Actúa como colaborador del Señor y de todas las mediaciones que coadyuvan a realizar históricamente en cada hombre el evangelio del amor, de la libertad y de la paz. Actúa también como avisado contrincante del avieso enemigo que trata de frustrar en cada uno esa senda de vida ${ }^{17}$.

Tobías realiza con el pez el ritual de sanación que le había enseñado Rafael para expulsar al demonio Asmodeo. Seguidamente, en la noche de bodas, la pareja reza ante Dios. Unen sus espíritus, antes de unir sus cuerpos ${ }^{18}$. Y el Señor les concede la curación. Tras varias

17 ARANA, «El acompañamiento espiritual», 66-67.

18 Comentaba san JuAn PABLo II con belleza a propósito de este pasaje: «El amor de Tobías debía afrontar desde el primer momento la prueba de la vida y de la muerte. Las palabras sobre el amor"fuerte como la muerte" (Cantar 8,6), que pronuncian los esposos del Cantar de los Cantares en el trasporte del corazón, asumen aquí el carácter de una prueba real. Si el amor se muestra fuerte como la muerte, esto sucede sobre todo en el sentido de que Tobías y, juntamente con él, Sara van sin titubear hacia esta prueba. Pero en esta prueba de la vida y de la muerte vence la vida, porque, durante la prueba de la primera noche de bodas, el amor, sostenido por la oración, se manifiesta más fuerte que la muerte» (Ciudad del Vaticano. Audiencia General. 27 de junio de 1984). 
vicisitudes, Tobías y Sara (y Rafael) emprenden el viaje de vuelta. En estos últimos capítulos, Rafael cada vez aparece menos. Sin embargo, aún toma la iniciativa en un momento oportuno para decirle a Tobías que se apresure, aunque Sara y sus criados vayan a su ritmo, para curar lo más pronto posible al anciano Tobit. Esta última recomendación de Rafael nos sugiere que, en ocasiones, los procesos de acompañamiento espiritual, especialmente los vocacionales, pueden demorarse demasiado. Las prisas son malas consejeras, pero también las demoras terminan por enfriar los corazones. El acompañante debe ser un sabio de los tiempos: debe pedirle al Señor que lo ilumine en la paciencia y en la urgencia, sin abreviar, pero tampoco sin dilatar las cosas. Al final, el joven es quien debe decidir a la luz de Dios, pero el acompañante debe decir, en ciertas situaciones, una palabra decisiva: « ¿No crees que es tiempo ya de decidir qué vas a hacer con tu vida?».

\section{LA PAGA DEL ACOMPAÑANTE: BENDICIÓN Y TRANSFERENCIAS}

Tras narrar el precioso reencuentro y la curación del padre, Tobit le recuerda a su hijo que debe pagar a aquel hombre que lo ha acompañado en el viaje. Él es fiel a los preceptos de la Ley (cf. Lev 19,13; Deut 24,14-15) y quiere dar su salario al misterioso acompañante. Más aún, Tobías le responde al padre que el regalo que le ha hecho Azarías-Rafael es inmenso y que, aún con la mitad de la herencia, no podría remunerarle tanto don. Deciden darle la mitad de los bienes. Pero Rafael reacciona recomendándoles otra cosa: «Bendecid a Dios y dadle gracias ante todos los vivientes por los beneficios que os ha concedido; así todos cantarán y alabarán su nombre. Proclamad a todo el mundo las gloriosas acciones de Dios y no descuidéis darle gracias» (Tob 12,6), además de otras recomendaciones para su vida: oración, ayuno, limosna, etc. (12,8-10).

En este pasaje, hay una recomendación de Rafael muy sugerente: «Es bueno guardar el secreto (mysterion) del rey, pero las gloriosas acciones de Dios hay que manifestarlas en público» (Tob 12,7). Por el «secreto del rey» debemos entender la acción salvadora de Dios en la historia de los hombres, una acción tantas veces escondida, pero revelada a su tiempo ${ }^{19}$. Así pues, el buen acompañante está llamado

19 Cf. Mc 4,11; 1 Cor 2,1.7; 4,1; 15,51; Rom 11,25; 16,25, etc. 
a ser un mistagogo, es decir, alguien que introduce al joven en los misterios divinos de la salvación, ayudándole, como Elí con el niño Samuel, a identificar la voz del Señor y responder a ella (cf. 1 Sam 3,1-21).

La réplica de Rafael a padre e hijo enseña que la mejor recompensa del acompañante es que el acompañado bendiga a Dios por el bien recibido y desarrolle una nueva vida de fidelidad al Señor. Una de las tentaciones del acompañante es, en cambio, esperar gratificaciones, pactar con las transferencias afectivas que se producen en la relación de acompañamiento ${ }^{20}$. Muchos acompañantes caen -yo, por lo menos, así lo he experimentado- en estas trampas del mal espíritu cuando se entristecen por no ser reconocido en su labor, o cuando no les agradecen lo que supone un buen servicio. Estas tristezas del corazón revelan un desempeño defectuoso del acompañamiento. La relación de ayuda, que debió comenzar con un discernimiento para identificar la voluntad de Dios y debió continuar con la oración con y por la persona acompañada, debe también acabar en la bendición gratuita y agradecida al único que debe ser reconocido: Dios.

Así se realizará no solo en el corazón del acompañado, sino también en el corazón del acompañante el itinerario de la salvación: pasar de la angustia y el desmayo personal a la bendición comunitaria por la gracia divina que es poder recorrer con otros el viaje de la vida. Note el lector del libro de Tobías que el final del relato termina con una amplia acción de gracias de Tobit $(13,1-14,1)$, en la que pasa de las vicisitudes personales de su familia a la realidad nacional de su pueblo. De la tristeza a la alegría, del yo al nosotros, de la angustia a la madurez... estos son algunos de los itinerarios indispensables que hay que recorrer en el viaje de la vida.

En definitiva, cuando Rafael, por fin, desvela a Tobit y Tobías que él es uno de los siete ángeles que están siempre presentes ante la gloria de Dios y ellos se postran en tierra, él les dice unas palabras que todo acompañante debería rezar muchas veces. Con ellas terminamos:

20 En el libro William A. BARRY - William J. CONNOLLY, La práctica de la dirección espiritual (Santander, Sal Terrae, 2011) se explica bien la espinosa cuestión de las transferencias en la relación de acompañamiento espiritual. 
Bendecid a Dios por siempre. Si he estado con vosotros no ha sido por mi benevolencia (charis), sino por la voluntad de Dios (te thelesei tou theou). ¡Bendecidlo por siempre!

(Tobías 12,18) 